\title{
Intellectual Management: An Integrative Theory
}

\author{
Dengke $\mathrm{Yu}^{1} \cdot$ Rong $\mathrm{Zhou}^{2}$
}

Received: 1 May 2015 / Accepted: 17 September 2015 /

Published online: 10 October 2015

(C) The Author(s) 2015. This article is published with open access at Springerlink.com

\begin{abstract}
Knowledge and character play similarly important roles in knowledge organizations. This paper aims to propose a novel management theory, Intellectual Management (IlM), which is an integration of knowledge management (KM) and character management (CM). Through case study, the management practices in three famous Chinese enterprises were summarized and comparatively analyzed. Taking the results and findings of case study into consideration, the authors built a theoretical model of IIM. As a conceptual framework, the IIM model is proposed and analyzed in terms of definition, function, process, tool, and feature. It was found that (1) IIM is rich in meaning that is constituted of five management levels including component, structure, mode, method, and target; (2) IlM would be embedded into the existing management functions such as strategizing, organizing, decision-making, motivating and controlling, and management subprocesses including research and development $(\mathrm{R} \& \mathrm{D})$, logistics, production, marketing and service; (3) an organization which properly engages in IIM would show some features, which could be introduced as evaluation criteria of IlM maturity; (4) the IIM could apply the prior management tools regarding to $\mathrm{KM}$ and $\mathrm{CM}$ or explore some new specific tool packages; and (5) currently, the organizational destiny is depended on the effective IlM which integrates and balances the roles of KM and CM. IIM is expected to be an effective management idea for knowledge-intensive organizations in future competitive environments.
\end{abstract}

Keywords Management - Intellectual management $\cdot$ Knowledge management · Character management · Integrative theory . Case study

Dengke Yu

yudengke@ncu.edu.cn

Rong Zhou

376219352@qq.com

1 School of Management, Nanchang University, 999 Xuefu Road, Honggutan New Zone, Nanchang City, Jiangxi Province 330031, China

2 School of Economics and Management, Jiangxi Science \& Technology Normal University, Jiangxi, China 


\section{Introduction}

Knowledge and character are important factors to one's fate. The phrase "knowledge is power," though it is cliché, is as true a statement as ever in today's knowledge environment (Henard and McFadyen, 2006), while another famous opinion "the personality decides destiny" applies equally to the modern. An enterprise, as an organic entity like a man (Wenping, 2004), also owns its unique knowledge and character, which shape its fortune. In fact, knowledge increases core competence while character enhances character competence for organizations (Resnick, 2003); these two kinds of competence are similarly important to firms. For instance, Microsoft is known for its core competence based on advanced technology but may with low score on character competence (Resnick, 2003).

Knowledge Management (KM) originating at the end of twentieth century (Jacques, 1996) is an important technique to manage knowledge resources and capabilities in organizations. Nowadays, it is a general and relatively mature management theory to academics and practitioners. KM has been proved effective to achieve competitive advantage for knowledge-based organizations in the era of knowledge economy (Kale and Karaman, 2011). However, KM in some organizations was also problematic, and KM initiatives failed (Chatti, 2012). Several enterprises (e.g., Nokia) with advantages in knowledge lost their competences because of insufficient character.

As a matter of fact, there is no clear definition about Character Management (CM) though a few of academics have paid attention to the importance of organizational character (Cooter and Eisenberg, 2001; Goffee and Jones, 1998; Moore, 2005; Sharma, 2002; Soriano, 2003). In practice, enterprises pay more attention to core competence on the basis of KM than character competence on the basis of CM (Resnick, 2003). However, currently, CM is urgently required since high technology and knowledge product open a new scope for character competition.

A novel theory integrating $\mathrm{KM}$ and $\mathrm{CM}$ is thus essential to the simultaneous exploration of knowledge and character in enterprises. This paper tries to propose a new theory which is called Intellectual Management ((IlM), which is to be different from Information Management, (IM)) based on the consideration of "IIM=KM+CM". The notion of IIM that only was simply mentioned by Ostapov (2012) is really novel. However, IlM redefined in this paper is totally different from the previous definition which mainly focused on optimal planning and adaptive control (Ostapov, 2012). Furthermore, it also different from intellectual capital management (Bukh et al., 2005; Isaac et al., 2010; Whyte and Zyngier, 2014) or intellectual property management (Bosworth and Webster, 2006; Fisher III and Oberholzer-Gee, 2013; Jennewein, 2004). An organization involved in IIM would be knowledge-intensive and characteristic for synchronously achieving core competence and character competence, which in turn guarantee its long-term competitive advantage.

The remainder of this paper is structured as follows. In Section Literature Review, literature of KM and CM was reviewed. The research methodology was presented in Section Methodology. Case study was done in Section Case study, and the integrative model of IlM was then built in Section Theoretical model development on the basis of findings. Conclusion, limitations and future work were finally summarized in Section Conclusions. 


\section{Literature Review}

\section{Knowledge Management}

KM has existed for a long time (Dave and Koskela, 2009). Since Wiig (1993), a pioneer in the field of KM, many experts have put forward a variety of KM definitions and ideas (O'Dell and Grayson, 1997; Tserng and Chang, 2008). Becerra-Fernandez and Sabherwal (2010) stated that "KM incorporates technical as well as social aspects," and it is a developing theory that includes "traditional approaches as well as emerging topics such as social networks, Web 2.0 and open innovation." Jashapara (2011) proposed that $\mathrm{KM}$ is an integrated approach of technological system and management process.

$\mathrm{KM}$ is a management system underpinned by information and communication technologies (ICTs) which enhance the management efficient of knowledge resources including individual knowledge, organizational knowledge, technological knowledge, etc. (Dave and Koskela, 2009; Ofek and Sarvary, 2001; Smith, 2001). Technological KM enablers include a number of ICTs, such as document management system, expert based system, information management system, decision support system, and communication and collaborative system (Chuang, 2004).

$\mathrm{KM}$ is a pragmatic guide to the design of knowledge-based processes and their integration into businesses (Hawryszkiewycz, 2010). As Gold et al. (2001) and Lee and Choi (2003) stated, KM processes mainly included four aspects: knowledge acquisition process, knowledge conversion process, knowledge application process, and knowledge protection process. Within these processes, there are a series of knowledge activities such as creating, searching, collaborating, organizing, storing, integrating, combining, retrieving, sharing, and securing (Gold et al., 2001). KM processes represent the basic operations of knowledge (Lee and Choi, 2003). KM performance is achieved when KM processes are efficiently embedded in organizational system to reduce cost, improve efficiency, and create value.

\section{Character Management}

The existence of corporate character was argued by several researchers. According to the literature of Goffee and Jones (1998), corporate character equals to its culture. Moore (2005) argued that "a virtuous corporate character is the seat of the virtues necessary for a corporation to engage in practices with excellence, focusing on those internal goods thereby obtainable, while warding off threats from its own inordinate pursuit of external goods and from the corrupting power of other institutions with which it engages." In fact, corporate character is a much wider notion involving the diversity of corporate strategy, the peculiarity of organizational culture, the specialty of corporate product, and the individuality of employees.

CM was not clearly defined in the past though many researchers studied the management approach for specific organizational characters such as strategy, leadership, culture, structure, affiliation, marketing, ethics, and individual character. From internal governance perspective, $\mathrm{CM}$ engages in organization operation and culture construction with excellence. First, the novel growth pattern which differentiates enterprises from rivals was emphasized to be developed for competence (Ding, 
2011). Second, character reflecting on leaders' preferences plays a role in leadership success and effectiveness (Klann, 2007). Third, to some extent, CM is culture governance. Different cultures with respective characters, for example, networked culture, mercenary culture, fragmented culture, and communal culture, concern the social architecture of organizational success or failure (Goffee and Jones, 1998). Fourth, affiliation character such as region, country, and ownership structure would be influential to organizational development (Collinson and Rugman, 2007; Soriano, 2003). Finally, CM also involves individual character management of employees (Chen, 2014). The relationship between individual character and organizational character is twofold: individual characters constitute organizational character, and organizational character leads and changes individual characters unconsciously (Wright and Goodstein, 2007).

From an external expression perspective, $\mathrm{CM}$ engages in value creation patterns and relationship management between the organization and external stakeholders, such as customers, shareholders, and public. First, enterprises producing personalized products or homogeneous products, low-quality products or high-quality products, and general products or brand products provide different value for customers, and in turn create various values for themselves. Character of customer choice and market location is vital for organizations (Porter, 1985). Second, the way to deal with the relationship between managers and shareholders would impact the development orientation and external credibility of organizations (Stout, 2012). Enterprises with different ownership characters gain different images, trusts, and competitive advantages (Bruque et al., 2003). Third, enterprises should protect environments, create value, and follow business ethics (Sharma, 2002) to be responsible for public. Public tends to have favorable attitude towards characteristic enterprises focusing on green growth, public benefit, customer value, and lawful operation.

\section{Methodology}

To discuss the existence and performance of IIM, three famous Chinese enterprises are selected for case study through comparative analysis since the IIM idea is full of oriental philosophic thinking which focuses on symmetry and complementation. The three organizations are from different knowledge-intensive industries: Giant Group which went bankrupt in 1997 was one of the most famous Chinese computer corporations at the end of the last century; Huawei Technologies Corporation (Huawei) generating $\$ 32$ billion in annual revenues in recent years and with offices in more than 140 countries is the most important and successful telecoms equipment maker in today's China (Steinbock, 2013); Hunan Satellite Television (HSTV) is by almost all measures the most successful television station in China behind only China Central Television (Barboza, 2005; Rosenthal, 2000).

Since Giant Group is the most controversial firm in Chinese business history and Huawei and HSTV are prides of Chinese, there are many detailed reports about them. Consequently, qualitative research and comparative study methodologies are mainly utilized to achieve the study objectives of this paper on the basis of second-hand data. The materials mainly include journal articles, newspaper articles, magazine articles, corporate reports, and useful website documents. Most of them were published in 
Chinese and are public for readers. A few of documents in English were reported in international journals and newspapers. In addition, a few detailed contents were added based on informal interview of some anonymous insiders who understood more about the cases.

\section{Case Study}

\section{Description of Cases}

\section{The First Case-Giant Group}

In the 1990s, Giant Group was one of the most well-known enterprises in China because of the rapid development and sudden bankruptcy (Zhou, 2002). The Giant Group was established in 1989, and the original business was a kind of printing system M-6401. This product was potential when the computer was beginning to popularize in China. In 1993, the Giant Group has become one of the most powerful computer firms. Giant Group and its founder Shi Yuzhu were valued by Chinese state leaders. However, the honors changed the mentality and character of Shi. He put a lot of investment in healthcare industry which brought much more profits rapidly at that time. Meanwhile, Giant Group started the construction project to build the highest office block in Zhuhai with no loan. Not surprisingly, Giant Group went bankrupt suddenly in 1997 because of capital chain break. Reviewing the development history, the prosperity and failure of Giant Group were all depended on Shi's character. There were obvious advantages and flaws in the individual character of Shi and organizational character of Giant Group.

The unique and inimitable individual characters such as concentration, persistence, self-confidence, autonomy, and integrity contributed to Giant's success. For example, Shi did not do other businesses when he concentrated on one thing. When he paid attention to develop business of online game, he did not make a decision for Naobaijin, another important business of Giant Group, though he was the biggest shareholder (Wang and Tian, 2009). Furthermore, Shi created many miracles especially in marketing by means of his own methods. When he designed the advertisement of the healthcare products, every employee in the advertisement planning department was required to interview more than 50 customers. He persistently paid attention to customer psychological analysis instead of improvement of products in advertisement. It was famous and surprisingly successful that Giant Group could realize competitive advantage repeatedly by illiberal advertisements. Giant Group and its healthcare products gave customers and public a kind of peculiar and delicate feeling, which formed the organizational image of Giant. In 2000, Giant was reestablished rapidly with the help of reputation and credibility of Shi. As a return, the new Giant promised to meet the liabilities when Giant Group closed down (Yu et al., 2008). Shi and the new Giant were characterized by integrity since then.

Giant Group's failure depended on its character flaws. The rapid development made the management systems of Giant incomplete, and most of important decisions were made only by Shi on the basis of individual leadership and spiritual charm. However, two character flaws of Shi guided Giant Group to a path of failure. One is military worship, and the other is self-conceit. In some time of Giant Group's life cycle, it was 
managed militarily. Military institutions such as headquarters and front armies were established to start three campaigns which meant sales promotion activities of three series of products - computer, healthcare product, and drug, under the general mobilization order of Shi (He, 2012). The large-scale lightning tactics was effective. The number of subsidiary corporations increased from 38 to 228 , and employees added from 200 to 2000 in less than half a year. The order quantity broke through CNY 3 hundred million. However, the rapid diversified development created some potential troubles. Giant Group had to reorganize and change many managers 1 year later. Even though these measures were taken, it was also serious that corporate profits were picked up by persons without permission. Military management did not contribute to strict and normative management systems. On the contrary, it brought troubles to scientific management in the condition of the mismatching of duty, right, and interest (Liu, 2008).

The self-conceit character reacted on the construction of Giant Building. This building was planned in 1992 to be 18 levels. Surprisingly, it was finally changed into 70 levels in consideration of establishing a landmark building in Zhuhai city. The fault was continuing because of the illusion of rapid development and the face-saving character. Giant Group promised that the building construction project would not borrow one penny from banks. Until May 1996, the profits of all subsidiary corporations were invested in the building. This decision caused the main profitable heathcare business to be difficult to develop sustainably (Liu, 2008). Finally, Giant Group faced the crisis of close-down due to incompletion of the Giant Building on schedule.

\section{The Second Case-Huawei}

Huawei was established in 1988 in Shenzhen City as a private enterprise during the peak of China's economic reforms and technological advancement (Low, 2007). It is now the largest telecom vendor in China and the world's largest supplier of Softswitch (Foster and Reinsch, 2010). In 2010, Fast Company reported by Forbes ranked Huawei the fifth most innovative company in the world. Huawei became one of 500 Fortune Companies in the world from 2011, and the ranking was up to 285 in 2014 (FORTUNEChina, 2014). Its products and services have been deployed in more than 170 countries, and nowadays, it serves 45 of the global 50 largest telecoms operators (Vance and Einhorn, 2011). What is driving Huawei's success? The answer is technological innovation. More accurately, it is not the innovation that drives Huawei's success, but the process that creates innovation drives success (De Cremer and Zhang, 2014).

Huawei is pouring massive amounts of resources into research and development (R\&D) (Foster and Reinsch, 2010). On its web site, Huawei claims to have 150,000 employees, and over $45 \%$ of them, about 70,000 are involved in R\&D (Huawei, 2014). Huawei has persisted investments in R\&D not less than $10 \%$ of sales for a long time (Li, 2010). In 2013, the investments were CNY 30.6 billion which were $12.8 \%$ of sales (Huawei, 2014). Even because of the low cost of Chinese talents, Huawei has had the luxury of being able to get much more research done, for the same amount of investment of its western rivals (Foster and Reinsch, 2010). In a sector where future growth and expansion is heavily dependent on R\&D, this makes Huawei globally competitive (Low, 2007). It has $16 \mathrm{R} \& \mathrm{D}$ institutes in countries including China, 
Germany, India, Russia, Sweden, and the USA and has established 34 joint innovation centers with leading operators (Huawei, 2014). Collectively, these R\&D activities have helped to propel Huawei onto the world stage (Low, 2007). Technological precedence is the core source of its business success and sustainable competitive advantage (Miao, 2007).

In the case of Huawei, innovation is an outcome rather than an antecedent (De Cremer and Zhang, 2014). Its innovativeness is demonstrated by its industrious acquisition of patents. In 2008, Huawei filed 1737 PCT international patent applications, which exceeded Panasonic and Philips to be No. 1 in the world. By the end of 2010, Huawei had filed 49,040 patent applications. Of the 17,765 authorized patent granted, 3060 were overseas patents (De Cremer and Zhang, 2014). Recent years, innovation boosted faster, and the quality of patents was improving. In 2014, the accumulative authorized patents increased up to 36,511. Huawei held $7 \%$ of $3 \mathrm{GPP}$ fundamental patents. In addition, it plays an important role in over 170 international standard organizations, for example, ITU, 3GPP, and ETSI, and open source groups, and has submitted about 20,000 documents.

It would be straightforward to observe that Huawei is innovative in nature and, therefore, successful (De Cremer and Zhang, 2014). Rather, the knowledge and innovative technologies are results of its values, vision, and procedures. To some extent, Huawei is also characteristic as well as knowledgeable. The innovativeness is one of the obvious characters of Huawei people. Another character is the directive leadership style of its chairman and founder, Ren Zhengfei, who is leading his company like an army.

\section{The third case-HSTV}

HSTV, which began broadcasting nationally by satellite in 1997, is now one of the most powerful television properties in China (Barboza, 2005). It won 40 national highest audience ratings in 2013. The audience rating of HSTV was ranked national No. 3 and the No. 1 among provincial satellite TV stations. The super-high television ratings in the most valuable prime-time programs and night shows prove the leading position of HSTV in terms of market awareness, brand strategy, innovative plan, and resources integration ( $\mathrm{Lv}$ and $\mathrm{Yu}, 2008$ ). On its web site, HSTV is characterized by youth, fashion, and happiness and is knowledgeably supported by integration of marketing innovation, creative plan, and talents. On the basis of integration of knowledge and character, HSTV shows its special intellectual character, which is of great brand value.

HSTV is full of unique characters. In 2002, HSTV was strategically positioned "locking entertainment, youth and the whole nation" to target national audiences. Aiming to "build the most creative television entertainment brand in China," it began to highlight the features of channel and pay attention to "the young, beautiful and fashionable". In 2003, HSTV was designated as the flag-carrier of Hunan TV \& Broadcast Intermediary Co. Ltd. (HTBI). "Happy China" was launched as a new positioning of HSTV in 2004 to further strengthen characteristics (Rosenthal, 2000). In the following years, a number of participatory programs including Super Girls, National Ping Pong Carnival, and Super Boys were produced and staged. In 2013, a novel theme "happy China and feel my youth" was proposed, and a lot of programs including self-control teleplays, variety shows, and large-scale recreational activities 
were produced to match the theme. In the end of 2013, a family program Where Are We Going? Dad made a good score on the basis of the theme "more grow, more youth". An upgrade flag "more happy reunion, more youth" was launched in 2014. The innovation, plan, and distribution of programs were improved to target the whole day audiences including audiences after 22 o'clock (Yi and Xiang, 2012). In addition, some other programs such as talent show Super Girls, variety show Happy Camp, idol drama Ugly Girl etc. were successful. The New Year's Eve concert targeted young people learned by dozens of satellite televisions has been the reception of TV champion for continuous 9 years. Because of its characteristic positioning like that, HSTV was always welcomed by younger generations.

HSTV's success is also supported by a series of knowledge activities and processes such as marketing innovation, creating planning, and integrative talent exploitation. HSTV originally created interactive marketing pattern and has won kinds of marketing awards including the Golden Tripod Award to Outstanding Marketers, Chinese Medium Innovative Marketing Award, Gold Award for Medium Marketing of Great Wall Award etc. HSTV even more received the honor of Four Dragons of Innovative Satellite Channel Cross Strait in 2014. In addition to the powerful marketing, its success depends on the perfect creative plan. The relative competitive advantage can be traced to the successful plans of various idol dramas, talent shows, and variety shows, some of which have become its well-known brands. There were also some awards for HSTV's creative plans, for example, the 2007 Outstanding Plan Team Award and the 2012 Fashionable Creative Plan Award. Furthermore, HSTV paid attention to integrating talents and resources. Its talent pool covered the excellent presenters such as He Jiong, some idol stars such as $\mathrm{Li}$ Yuchun, famous administrators such as Wei Wenbin, and high-level program producers such as Long Danni (Ouyang, 2008). Only the cooperation of those talents made its programs popular. Based on the mighty platform, powerful innovation capability, and rich experience in program innovation, unique programming, and brand resources integration, HSTV realized the harvest of both advertisement revenue and public praise. Thereby, not surprisingly, HSTV became one of the 500 most valuable brands fortunately.

\section{Results}

\section{Holistic View}

The three enterprises are set in three different quadrants (Fig. 1) in four quadrants which are defined in terms of two dimensions - knowledge and character. Giant Group is high score in character but relatively low score in knowledge since the knowledge-intensive computer business was only a small part of its business portfolio. Huawei is opposite, with high score in knowledge and relatively low score in character though its management style is also characteristic. It is amazing that Ren Zhengfei (Huawei's chairman) and Shi Yuzhu (Giant Group's founder) chose the similar military leadership style but their companies faced totally different destinies. Only the HSTV with high scores in both two dimensions is the most proper. These enterprises represent the role of the 


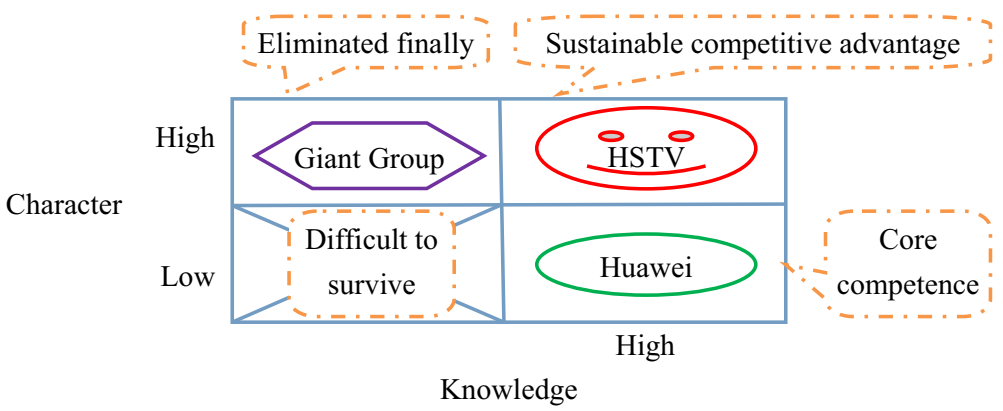

Fig. 1 The classification of sample enterprises and their destinies

integration of $\mathrm{KM}$ and $\mathrm{CM}$ in different development stages. The enterprises in the remaining quadrant are unnecessary to consider because they would not survive in intense competition for a long time.

The three case enterprises faced respective destinies because of their different decisions on management style. Obviously, an enterprise without characteristic and knowledge is difficult to survive. However, an organization with too forceful characteristic but relatively less knowledge may attract customers in a short time, but it would be obsoleted finally due to the shortage of core competence. Giant Group is an example. Comparatively, a firm such as Huawei, which invested massively in knowledge innovation activities, gained much better performance. Huawei has cultivated its core competence by knowledge innovation. It is more important that Huawei did not go to extremes in character development, and thereby, it always made right decisions. HSTV is certainly the best example of integration of KM and CM because it not only has distinctive character and accurate positioning but also is supported by a lot of knowledge resources especially including many talents. HSTV is enhancing the sustainable competitive advantage, precisely on the basis of the supplementary effects of $\mathrm{KM}$ and $\mathrm{CM}$.

\section{Management Level}

From the perspective of management level in terms of component, structure, mode, method, and target, Giant Group, Huawei, and HSTV were of significant differences, as shown in Table 1. HSTV was almost perfect in terms of various levels of management. Huawei has done a good job especially of R\&D management. Giant Group had advantages at the beginning but moved towards failure finally because of its characteristic flaws. Obviously, CM and KM are all vital to organizations and their integration would be more advantageous. However, knowledge is relatively more important than characters because an organization should primarily pay great attention to selfoptimization supported by knowledge creation rather than showing characters. In addition, along with the creation and accumulation of knowledge, a sort of significant characteristic, innovativeness, will appear naturally. The knowledgeable and innovative Huawei is a good example for that. When Huawei did well in knowledge innovation, it developed and showed the characters at the same time. Generally, a well-organized enterprise (e.g., Huawei) will show proper mental appearance to public and stakeholders. 
Table 1 Management levels of the cases

\begin{tabular}{|c|c|c|c|}
\hline Level & Giant Group & Huawei & HSTV \\
\hline Component & $\begin{array}{l}\text { Advantages in technological } \\
\text { R\&D at the beginning, but } \\
\text { lack of sustainable KM. } \\
\text { Distinct characteristics. The } \\
\text { advantages and flaws were } \\
\text { equally obvious. }\end{array}$ & $\begin{array}{l}\text { Sustainable R\&D } \\
\text { investments and KM. } \\
\text { Brand characteristics } \\
\text { and organizational image } \\
\text { on the basis of } \\
\text { technological advantage. }\end{array}$ & $\begin{array}{l}\text { Rich knowledge in terms } \\
\text { of talents, creative plan } \\
\text { and innovative marketing. } \\
\text { Accurate and effective } \\
\text { character positioning, } \\
\text { and therefore distinct } \\
\text { characteristics. }\end{array}$ \\
\hline Structure & $\begin{array}{l}\text { Advantages in external } \\
\text { management involving in } \\
\text { marketing, advertisement } \\
\text { and new products } \\
\text { positioning. Disadvantages } \\
\text { in human resource } \\
\text { management, customer } \\
\text { relationship management, } \\
\text { supply chain management, } \\
\text { financial management and } \\
\text { organizational system } \\
\text { design. }\end{array}$ & $\begin{array}{l}\text { Proper internal management } \\
\text { in technological innovation } \\
\text { to win core competence. } \\
\text { Good work in managing } \\
\text { external image, brand and } \\
\text { stakeholders to cultivate } \\
\text { sustainable competitive } \\
\text { advantage. }\end{array}$ & $\begin{array}{l}\text { Proper internal management } \\
\text { in terms of knowledge } \\
\text { resources integration and } \\
\text { innovation. Perfect } \\
\text { customer positioning to } \\
\text { youth and entertainment. } \\
\text { Successful managing } \\
\text { image and brand. Full } \\
\text { of characters. }\end{array}$ \\
\hline Mode & $\begin{array}{l}\text { Individual and perceptual } \\
\text { decisions made by the } \\
\text { founder caused to the } \\
\text { final failure. }\end{array}$ & $\begin{array}{l}\text { Rational decision-making } \\
\text { based on knowledge } \\
\text { discovery, professional } \\
\text { management and } \\
\text { independent audit. }\end{array}$ & $\begin{array}{l}\text { Integration of expert-aided } \\
\text { decision and rational } \\
\text { decision. Combination } \\
\text { of decision-making, } \\
\text { performance evaluation } \\
\text { and effective motivation. }\end{array}$ \\
\hline Method & $\begin{array}{l}\text { Mainly depends on traditional } \\
\text { management techniques. }\end{array}$ & $\begin{array}{l}\text { Mainly depends on } \\
\text { information technologies } \\
\text { such as a complete R\&D } \\
\text { management system } \\
\text { introduced from IBM. }\end{array}$ & $\begin{array}{l}\text { Integration of management } \\
\text { theories and modern } \\
\text { information management } \\
\text { technologies. }\end{array}$ \\
\hline Target & Fail to achieve the goals. & $\begin{array}{l}\text { Successful internal growth on } \\
\text { the basis of technological } \\
\text { precedence. }\end{array}$ & $\begin{array}{l}\text { Success in both characteristic } \\
\text { development and internal } \\
\text { growth. }\end{array}$ \\
\hline
\end{tabular}

\section{Management Function}

From management function perspective, the three enterprises made big differences too (Table 2). Giant Group almost had problems in terms of every management function, for example, short in strategy, over-reliance organization, perceptual decision-making, failing motivation, and unordered control. Hence, it was not surprising that Giant went bankrupt when it was massively expanding. Huawei's management functions focused on R\&D activities and knowledge innovation. This management style was proved efficient in a knowledge-intensive sector. It is much more difficult to manage an organization like HSTV since it gave consideration to both KM and CM. Every management function should be proper to guarantee the realization of management targets and performance. Indeed, sometimes the objectives of KM and CM would be conflicting, but much experience also could be collected to implement and popularize $\mathrm{KM}$ as well as CM. 
Table 2 Management functions of the cases

\begin{tabular}{|c|c|c|c|}
\hline Function & Giant Group & Huawei & HSTV \\
\hline Strategizing & $\begin{array}{l}\text { Ambitious but not } \\
\text { strategic. Its three } \\
\text { businesses could } \\
\text { not support each } \\
\text { other and thereby } \\
\text { capital chain broke } \\
\text { because of a short } \\
\text { in strategy. }\end{array}$ & $\begin{array}{l}\text { Carry out long-term } \\
\text { strategy on the basis } \\
\text { of technological } \\
\text { advantage. Its strategy } \\
\text { is to win by technological } \\
\text { innovation. }\end{array}$ & $\begin{array}{l}\text { The strategy positioning } \\
\text { "youth, fashion and } \\
\text { happiness" is accurate and } \\
\text { clear. The strategy can be } \\
\text { implemented based on } \\
\text { integrating resources } \\
\text { including talents, } \\
\text { technologies, funds and } \\
\text { brand, etc. }\end{array}$ \\
\hline Organizing & $\begin{array}{l}\text { Individualistic heroism } \\
\text { and military style } \\
\text { management. The } \\
\text { resources were } \\
\text { organized by } \\
\text { individual ability } \\
\text { of its founder, Shi. }\end{array}$ & $\begin{array}{l}\text { Knowledge-based, } \\
\text { networked and distributed } \\
\text { organization. Effective } \\
\text { leading. Authorities are } \\
\text { harmoniously centralized } \\
\text { and decentralized. }\end{array}$ & $\begin{array}{l}\text { Knowledge-based organized } \\
\text { on the basis of social } \\
\text { networks. Intellectual } \\
\text { leading which is beneficial } \\
\text { to exploring, integrating } \\
\text { and utilizing talents. }\end{array}$ \\
\hline Decision-making & $\begin{array}{l}\text { Perceptual decision- } \\
\text { making which } \\
\text { caused some faults. }\end{array}$ & $\begin{array}{l}\text { Rational decision-making } \\
\text { based on advanced } \\
\text { decision aid platforms } \\
\text { and team efforts. }\end{array}$ & $\begin{array}{l}\text { Integration of perceptual and } \\
\text { rational decisions which is } \\
\text { scientific and flexible. }\end{array}$ \\
\hline Motivating & $\begin{array}{l}\text { Failing motivation } \\
\text { gave rise to various } \\
\text { problems such as } \\
\text { disciplinary offense } \\
\text { and corruption. }\end{array}$ & $\begin{array}{l}\text { Systematical motivation } \\
\text { plan increased many } \\
\text { R\&D achievements. }\end{array}$ & $\begin{array}{l}\text { Systematical and specific } \\
\text { motivation measures in } \\
\text { terms of creative planning, } \\
\text { program hosting, stars } \\
\text { cultivating and } \\
\text { programming, etc.... }\end{array}$ \\
\hline Controlling & $\begin{array}{l}\text { Unordered financial } \\
\text { controlling which } \\
\text { was not fit for strategic } \\
\text { adjustment caused } \\
\text { corruption and capital } \\
\text { chain break, and } \\
\text { thereby failure. }\end{array}$ & $\begin{array}{l}\text { According to Internal } \\
\text { Control Manual of } \\
\text { Huawei Company } \\
\text { (Huawei, 2011), there } \\
\text { is systematical } \\
\text { internal control plan } \\
\text { in terms of organization, } \\
\text { finance, production, } \\
\text { marketing, administration, } \\
\text { IT, R\&D, public relations } \\
\text { and foreign investment. }\end{array}$ & $\begin{array}{l}\text { To show its characters and } \\
\text { produce personalized } \\
\text { programs, internal control } \\
\text { plan changed repeatedly. } \\
\text { However, some problems } \\
\text { also existed and impacted } \\
\text { the profits. }\end{array}$ \\
\hline
\end{tabular}

\section{Management Process}

Three enterprises have their own advantages and disadvantages in management processes (Table 3). In fact, most of Giant Group's management processes were effective especially to attract customers and expand markets. Giant Group paid attention to R\&D though it did not invest as much as Huawei in R\&D. However, real problems including insufficient cooperation existed in Giant's management process. Huawei did well in every management subprocess. Supported by knowledge resources and knowledge networks, Huawei's management was smooth and successful. The shortage of uncharacteristic products was covered by its characteristic services. More importantly, the 
Table 3 Management process of the cases

\begin{tabular}{|c|c|c|c|}
\hline Process & Giant Group & Huawei & HSTV \\
\hline $\mathrm{R} \& \mathrm{D}$ & $\begin{array}{l}\mathrm{R} \& \mathrm{D} \text { and upgrade of } \\
\text { products on the basis } \\
\text { of technological } \\
\text { advantage. }\end{array}$ & $\begin{array}{l}\text { Technological advantage } \\
\text { supported by sustainable, } \\
\text { powerful and high-quality } \\
\text { R\&D activities. It is } \\
\text { knowledgeable but } \\
\text { relatively not characteristic } \\
\text { enough. }\end{array}$ & $\begin{array}{l}\text { The core is creative plan. } \\
\text { It showed positioned } \\
\text { characters based on creative } \\
\text { plan, which integrated CM } \\
\text { and KM. }\end{array}$ \\
\hline Logistics & $\begin{array}{l}\text { Rapid expanding of } \\
\text { distribution channels, } \\
\text { but short in knowledge } \\
\text { and technology } \\
\text { cooperation. }\end{array}$ & $\begin{array}{l}\text { Strategic cooperation among } \\
\text { organization, suppliers and } \\
\text { distributors. }\end{array}$ & $\begin{array}{l}\text { Proper cooperation with other } \\
\text { media corporations, which } \\
\text { is the foundation of } \\
\text { producing high-quality and } \\
\text { characteristic programs. }\end{array}$ \\
\hline Production & $\begin{array}{l}\text { Three independent businesses } \\
\text { without collaboration in } \\
\text { production process. The } \\
\text { characters of different } \\
\text { products were not unified. }\end{array}$ & $\begin{array}{l}\text { Providing a series of products } \\
\text { in terms of information and } \\
\text { communication solutions, } \\
\text { and telecommunications. Its } \\
\text { products are technological } \\
\text { and standard, but not } \\
\text { characteristic. }\end{array}$ & $\begin{array}{l}\text { The programming process and } \\
\text { programs are all } \\
\text { characteristic to realize the } \\
\text { strategic targets. The } \\
\text { production process is } \\
\text { integrated in character } \\
\text { shaping process. }\end{array}$ \\
\hline Marketing & $\begin{array}{l}\text { It was famous for characteristic } \\
\text { marketing. However, its } \\
\text { advertisements are } \\
\text { controversial. }\end{array}$ & $\begin{array}{l}\text { Has created a successful } \\
\text { three-dimensional } \\
\text { marketing technique, } \\
\text { which is advantageous } \\
\text { in foreign marketing. } \\
\text { The advantage of } \\
\text { marketing talents and } \\
\text { networked resources makes } \\
\text { its marketing characteristic. }\end{array}$ & $\begin{array}{l}\text { A personalized marketing } \\
\text { thinking based on } \\
\text { professionally differentiated } \\
\text { marketing and resources } \\
\text { integration. The marketing } \\
\text { aims to establish } \\
\text { characteristic brand and } \\
\text { image on the basis of } \\
\text { knowledge innovation. }\end{array}$ \\
\hline Service & $\begin{array}{l}\text { The idea of service was not } \\
\text { clear. }\end{array}$ & $\begin{array}{l}\text { Separate service from products } \\
\text { to generate service } \\
\text { solutions including } \\
\text { consultation service, } \\
\text { network integration service, } \\
\text { management service and } \\
\text { network deployment } \\
\text { service, etc. }\end{array}$ & $\begin{array}{l}\text { A characteristic service } \\
\text { marketing pattern which } \\
\text { has integrated service and } \\
\text { marketing. Its customer- } \\
\text { orientated marketing aims } \\
\text { to provide convenient, } \\
\text { unique and high-quality } \\
\text { services for young } \\
\text { customers. }\end{array}$ \\
\hline
\end{tabular}

customers of Huawei have lower requirements on personality since generally the telecommunication equipments are required to be standard. HSTV was well done in integration $\mathrm{CM}$ and $\mathrm{KM}$ processes. On the one hand, its management paid attention to creative plan and knowledge resources (e.g., talents and knowledge networks) integration. On the other hand, the management processes always centered on the character positioning to shape its young, fashionable, and happy image.

\section{Management Tool}

Three enterprises have introduced their own management tool packages involving in KM and CM (Table 4). There is no significant difference among three enterprises' 
Table 4 Management tools of the cases

\begin{tabular}{|c|c|c|c|}
\hline Tools & Giant Group & Huawei & HSTV \\
\hline $\begin{array}{l}\text { Tool package } \\
\text { regarding } \\
\text { to } \mathrm{KM}\end{array}$ & $\begin{array}{l}\text { Did not use modern } \\
\text { KM systems to aid } \\
\text { management. }\end{array}$ & $\begin{array}{l}\text { Has built systematical } \\
\text { information management } \\
\text { platforms such as intranet, } \\
\text { extranet, web portals, expert } \\
\text { database and R\&D } \\
\text { management system. } \\
\text { Especially, the Integrated } \\
\text { Products Development } \\
\text { (IPD) process introduced } \\
\text { from IBM has played an } \\
\text { important role. }\end{array}$ & $\begin{array}{l}\text { Has introduced information } \\
\text { management system and } \\
\text { thorough communication } \\
\text { platform. It has advantages } \\
\text { in talent pool and plan } \\
\text { techniques. }\end{array}$ \\
\hline $\begin{array}{l}\text { Tool package } \\
\text { regarding to } \\
\mathrm{CM}\end{array}$ & $\begin{array}{l}\text { Insufficiently managed } \\
\text { characters had obvious } \\
\text { advantages as well as } \\
\text { disadvantages. }\end{array}$ & $\begin{array}{l}\text { Was characterized by mature } \\
\text { and leading technologies. } \\
\text { Paid attention to managing } \\
\text { characteristic services based } \\
\text { on service innovation. }\end{array}$ & $\begin{array}{l}\text { Super CM techniques helped } \\
\text { to gain competitive } \\
\text { advantages in characteristic } \\
\text { business, brand cultivation } \\
\text { and image shape. }\end{array}$ \\
\hline
\end{tabular}

management tools. Indeed, it was an improving process that Huawei and HSTV had been establishing relatively proper management technology systems in recent years. Suppose Giant could survive nowadays, it would do the same thing to introduce various management assistance systems. Surely, Huawei has the largest advantage in KM. In fact, there is no specific tool to aid CM since CM is an idea rather than a kind of technique or technology. However, it is obvious that HSTV can control, manage, and show its characters better. It is seen that some technologies and tools are required to implement the new theory proposed in this paper.

\section{Management Feature}

There are different management features in terms of organization, mechanism, culture, talent, and capital of the three organizations (Table 5). Collaboration relied on team's power seems to be more favorable than centralized organizations (e.g., Giant Group). Cooperative, competitive and adaptive mechanisms (for example, in Huawei and HSTV) are required in management. Learning, sharing, and innovating knowledge ought to be guaranteed by the culture. Sufficient knowledge-based talents are always necessary. Intellectual capital and social capital are equally important to knowledgeintensive organizations. To some extent, it can be seen that the features of knowledgebased organizations are criteria to evaluate the maturity of organizational management. From the comparative study of the three enterprises' management features, HSTV and Huawei seem to be obviously more mature than Giant Group in integration of KM and CM.

\section{Findings}

From the above analysis, the findings can be briefly summarized as follows.

First, KM and CM are all important to the sustainable competitive advantage of modern organizations. KM aims to improve technological innovation while $\mathrm{CM}$ 
Table 5 Management features of the cases

\begin{tabular}{|c|c|c|c|}
\hline Feature & Giant Group & Huawei & HSTV \\
\hline Organization & $\begin{array}{l}\text { Power is over centralized, } \\
\text { and organization is not } \\
\text { open enough. }\end{array}$ & $\begin{array}{l}\text { Open and collaborative with } \\
\text { other organizations. } \\
\text { Distributed teams formed a } \\
\text { networked organization on } \\
\text { the basis of ICTs and } \\
\text { cooperative R\&D platform. }\end{array}$ & $\begin{array}{l}\text { Resources are internally } \\
\text { integrated and } \\
\text { synergistically innovated } \\
\text { based on collaborative } \\
\text { networks constituted by } \\
\text { various performing arts } \\
\text { companies, actors and } \\
\text { artists, etc. }\end{array}$ \\
\hline Mechanism & $\begin{array}{l}\text { Unharmonious and } \\
\text { unordered management } \\
\text { systems were short in } \\
\text { flexibility and adaptation. }\end{array}$ & $\begin{array}{l}\text { Balance of cooperation and } \\
\text { competition. Strong adaption } \\
\text { ability to environment } \\
\text { changes. }\end{array}$ & $\begin{array}{l}\text { Programs support each other. } \\
\text { Team work. Sustainable } \\
\text { development based on } \\
\text { continuous creative plan. }\end{array}$ \\
\hline Culture & $\begin{array}{l}\text { Innovative culture, but } \\
\text { without enough attention } \\
\text { on knowledge sharing. }\end{array}$ & $\begin{array}{l}\text { Culture characterized as wolf } \\
\text { group; learning, innovating, } \\
\text { profiting and uniting. Strong } \\
\text { team spirit. }\end{array}$ & $\begin{array}{l}\text { Resources integration and } \\
\text { knowledge coordination } \\
\text { on the basis of shared } \\
\text { and innovative culture. }\end{array}$ \\
\hline Talent & $\begin{array}{l}\text { A group of technological } \\
\text { and entrepreneurial talent } \\
\text { at the beginning. Over } \\
\text { expansion in later period. }\end{array}$ & $\begin{array}{l}\text { Knowledge-based and - } \\
\text { intensive talents. } 47 \% \\
\text { employees involve in R\&D. } \\
\text { The items such as region and } \\
\text { knowledge structure of } \\
\text { talents are complementary. }\end{array}$ & $\begin{array}{l}\text { A rich talent pool covers } \\
\text { excellent planners, hosts, } \\
\text { managers and stars } \\
\text { and so on. }\end{array}$ \\
\hline Capital & $\begin{array}{l}\text { A few advantages in } \\
\text { intellectual capital and } \\
\text { social capital. }\end{array}$ & $\begin{array}{l}\text { Obvious advantages in } \\
\text { intellectual capital as well } \\
\text { as social capital. }\end{array}$ & $\begin{array}{l}\text { Rich social capital and } \\
\text { comparatively abundant } \\
\text { intellectual capital. }\end{array}$ \\
\hline
\end{tabular}

engages in construction of brand and optimization of corporate image. Enterprises integrating KM and CM will sustainably develop, for example, HSTV. On the contrary, enterprises (e.g., Giant Group) with low score both in knowledge and character dimension will be hard to survive in competition. Some specific knowledge-intensive enterprises such as Huawei may gain core competence on the basis of excellent KM, though its CM is not so developed.

Second, management involved in knowledge-intensive organizations includes five levels, namely: component, structure, mode, method, and target. KM and CM constitute the management system which focuses on internal and external management of organizations. Enterprises make decisions according to experts' experience and knowledge analysis. Management theories and information technologies are embedded in management process. Enterprises target to internal growth and characteristic development together.

Third, enterprises are involved in characteristic management functions including strategizing, organizing, decision-making, motivating, and controlling through the integration of KM and CM. An excellent enterprise, for example, HSTV, would involve differentiated strategy underpinned by knowledge capability, knowledge-based organization supported by social networks and knowledge networks, compound decisionmaking, systematical motivation focusing on $\mathrm{KM}$ and $\mathrm{CM}$, and dynamic controlling and feedback based on knowledge collection. 
Fourth, the integrative management of $\mathrm{KM}$ and $\mathrm{CM}$ is different from traditional management in terms of management process. In R\&D subprocess, the R\&D management takes technological level and diversified demand into consideration. The logistics subprocess is a vital process on the basis of cooperation in supply chain. Enterprises produce knowledge-based as well as characteristic products. Marketing is to build a characteristic brand instead of only sales promotion under the condition of product and service innovation based on knowledge innovation. Meanwhile, enterprises try to provide high-quality and characteristic after-sale services.

Fifth, tool packages regarding to $\mathrm{KM}$ and $\mathrm{CM}$ are employed in organizational management. Tools for KM include information and knowledge management platforms such as intranet, extranet, web portals, expert database, and R\&D management system which focus on management of various knowledge resources in organizations. Tools for $\mathrm{CM}$ help to gain competitive advantages in characteristic business, brand cultivation, and image shape.

Finally, enterprises are of special features such as open and networked organization, harmonious and flexible mechanism, innovative and shared culture, knowledge-based and knowledge-intensive talents, and intellectual and social capital.

All in all, knowledge and its management as foundation are essential to knowledgeintensive organizations, and the assistant CM would be an effective way to improve their performance. It can be confirmed that the integration of $\mathrm{KM}$ and $\mathrm{CM}$ is beneficial to the development of core competence and sustainable competitive advantage for organizations. The IIM theory integrating KM and CM proposed in this study is worth to be explored, exploited, and popularized.

\section{Theoretical Model Development}

\section{Definition of IIM}

IIM is rich in connotation. In this study, IlM is defined as follows: IlM, which is characterized by diversified features in terms of organization, mechanism, culture, talent, and capital, is a management technique integrating $\mathrm{KM}$ and $\mathrm{CM}$ underpinned by a package of systematic tools to achieve special management functions through knowledge-based and characteristic management processes; it expands internal management to external management to realize the twofold targets, namely: internal growth and characteristic development. In order to be beneficial to implementation and systematical thinking of the IIM, the management levels such as structure, mode, method, and target are discussed in this section.

\section{The Components of IIM}

The components of IlM include KM and CM. KM engages in learning, sharing, and utilizing knowledge resources which have been embedded in the mind of employees, organizational systems, and technological platforms. KM pays attention to managing the acquired behaviors such as learning and innovation. On the contrary, CM focuses more on leading and managing natural endowments such as the long-standing culture, value orientation, and work style, which have existed at the beginning of the new 
businesses and continuously evolve in process of development. Hence, CM's characters are twofold: congenital strategic positioning, and acquired path dependence. KM can improve organization in a relative short time by some investments in KM activities and processes, while CM needs a long-term guidance. The organizational inertia will resist the wider margin of character change. From another point of view, KM concentrates on promoting organizational productivity, and CM devotes itself to improving productive relations in enterprises. It is the harmony and coadaptation of productivity and productive relations to support rapid development of firms. Consequently, KM and CM are complementary to a great extent. The IIM integrating $\mathrm{KM}$ and $\mathrm{CM}$ will be proper management thinking for enterprises.

\section{The Structure of IIM}

IlM expands internal management to external management (Ostapov, 2012). Organizational characters, for example, corporate image and management style, are more of a kind of external performance, which can be felt and accepted by external entities. However, KM is a kind of internal management supported by the core knowledge resources which are confidential and valuable for organizations. Like a big tree, IIM is constituted of KM, which is the root in the deep underground and CM like leaves, which interact with external environment. IIM requires to manage internal knowledge as well as control external characters. The target of internal management is to promote organizational core competence by knowledge innovation, organizational innovation, and product innovation, and in turn, providing knowledge-intensive products or services for customers. The aim of external management is to improve organizational image and brand value, which are important sources of differentiated competitive advantage, by propagandizing culture and managing relations with stakeholders such as employees, customers, and suppliers. Thereby, the IIM structured with internal management and external management takes advancing core competence as well as competitive advantage into consideration.

\section{The Mode of IIM}

As the thought of Immanuel Kant, a famous philosopher, intellectuality is a sort of cognitive competence between sensibility and sense (Kant et al., 2007). Accordingly, from mode perspective, the IIM covers perceptual management and rational management. Herbert Simon, a known managerialist, proposed that "management is decision" (Simon, 1977). There are two decision-making ways: the first one is perceptual decision-making based on instinct, past experience, or organizational intelligence; and the second one is rational decision-making on the basis of knowledge, models, methods, survey, and discussion and so on. The scientificity and validity of perceptual management, which is often utilized by traditional enterprises and middle and small-sized firms, depend on the perceptual cognition of leaders or decision-makers. Rational management, which is supported and guaranteed by organization systems, is a kind of normalized and specialized management pattern in contrast. Perceptual management and rational management have their respective advantages: the former is beneficial to adjusting strategy, seizing opportunity, and embodying humanistic care; and the latter is in favor of avoiding risks from innovation and management and designing a long-term and macro strategy. Indeed, it is required the two kinds of management modes in the same enterprise, and to some extent, they should be complementary. It 
would be a proper decision-making pattern that determining a probable development orientation under perceptual management is followed by a specific implementation scheme based on rational analysis.

\section{The Method of IIM}

How to realize IlM? The method is a combination of management techniques and information technologies. The management techniques include materialism and dialectics, economic thoughts, and management theories. The information technologies cover information systems and platforms, such as expert systems, management information systems (MIS), intranet, extranet, business intelligence (BI) platform, etc. Decisions are made under the guidance of management techniques while information technologies assist the implementation. Under the context of intense competition, decision-making requires not only the knowledge and experience of managers but also the technological platforms to collect data, process information, and aid decision-making. Consequently, the main content of IIM is integrating techniques and technologies to play the role of experts' experience, knowledge, and technologies. The IlM engages in realizing the role of knowledge by utilizing knowledge-based technologies and reflecting organizational characters by integrating management techniques to make decision-making scientific and artistic.

\section{The Target of IIM}

The targets of IlM are twofold: for one thing, organizations are aimed at characteristic development with characters of differentiation and specificity; for another, organizations focus on innovation-oriented internal growth to seek sustainable competitive advantage. To win stable markets and profit pools, characteristic development makes organizations different form rivals and shapes brand image by differentiation strategy. Internal growth means continuous enhancement of core competence and evolution accompany with markets by unceasing knowledge accumulation and innovation. Characteristic development is achieved by integrating organizational characters into products and in turn enhancing customer perceived value, while internal growth is realized by embedding valuable and functional knowledge in products and in turn increasing added value. The two targets of IIM promote each other. This relationship contributes to the management and development of organizations.

To sum up, the IlM theory can be structured as five levels which is enriched and deepened gradually. The first one is foundation level constituted by KM and CM. The second one is organization level structured by external management and internal management. The third one is operation level supported by perceptual management and rational management. The fourth one is platform level constructed by management techniques and information technologies. The last one is realization level to achieve the targets of characteristic development and internal growth. These five levels can guarantee the successful realization of IIM (Fig. 2).

\section{IIM Functions}

Management functions are important to a systematic management theory. According to traditional management theory, management functions are always divided into items 


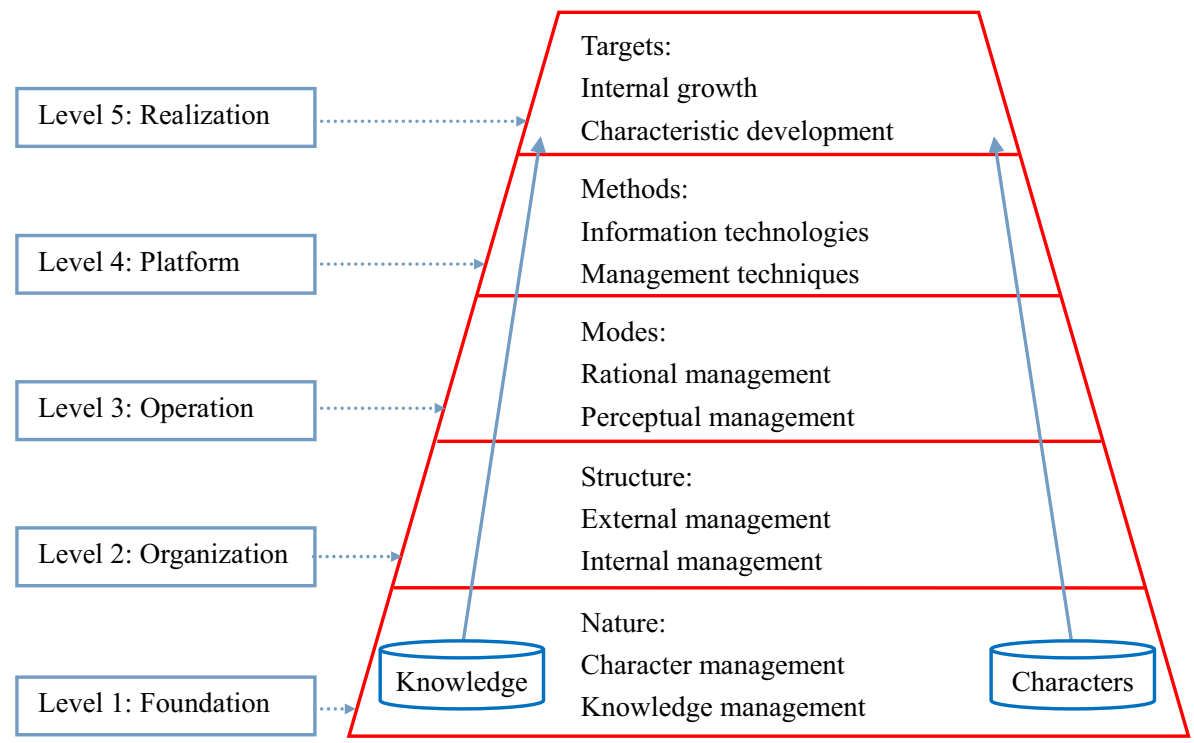

Fig. 2 The five levels of IIM

such as planning, leading, decision-making, motivating, and controlling (Combe, 2014; Schermerhorn Jr et al. 2014). To implement the IlM, its functions would be analyzed from perspective of integrating $\mathrm{KM}$ and $\mathrm{CM}$. The functions cover five aspects.

\section{Intellectual Strategizing and Planning}

When making strategy, enterprises which invest in IIM should pay attention to developing and displaying their intellectual character, in addition to realizing goals, wining core competence and gaining sustainable competitive advantage. In other words, the intellectual strategy is a comprehensive action including goals of internal growth and external responsibility. The enterprises should focus on self-improvement and public service to beautify their images. The key points of intellectual strategy are creating brand and improving image based on knowledge innovation and diversified competition, which can satisfy the functional requirements and psychological needs of customers. The proper intellectual planning should be rolling plan, which can effectively balance stability and change of the plan. The planning also should be flexible and self-optimized. It is appropriate to formulate outlines of plan on the basis of characters and then to design specific plan according to the progress of knowledge innovation. Intellectual planning ought to put the twofold targets into practice and pay attention to knowledge innovation and highlighting characters. That is, the core businesses are planned R\&D and marketing.

\section{Intellectual Leading and Organizing}

The suitable organizational structure of IIM is informal network organization which links and unites knowledge employees in contexts of knowledge networks and social networks. The KM activities and innovation processes are completed on the basis of psychological contract and humanistic management. The managers should be expert- 
type leaders with high scores of technological level as well as management ability and personal charisma. This type of leader, who especially cares spiritual life and development environment of employees, can be a good guide and trustworthy person for knowledge workers concerning career development. In addition, the intellectual leading pays great attention to interpersonal communication and character building. The intellectual leading not only leads but also guides the talents to drive intellectual organizations.

\section{Intellectual Decision-Making}

Intellectual decision-making is a process to research, form, and choose the best solutions to solve problems by utilizing perceptual (qualitative) and rational (quantitative) methods in current conditions. The process includes three subprocesses. First, it is a perceptual decision-making subprocess that targets and orientations are proposed on the basis of situations and strategies by leaders. Second, a rational decision-making subprocess is executed based on surveys and modeling to obtain advisable schemes and suggestions. Third, the final decision is selected by leaders in terms of their past experience and instinct. Perceptual decision-making is beneficial to play the role of leaders' experience, character, and preference. Conversely, rational decision-making can guarantee the scientificity of decisions on the basis of data, information, and knowledge. The two different decision-making methods shape the artistry and normalization characters of IIM. Intellectual decision-making, an artistic process with interaction between leaders and employees, engages in the fine balance of leaders' aspirations and employees' wills. Hence, the IIM also contributes to improve the executive force of the selected decisions.

\section{Intellectual Motivation}

Intellectual motivation is to stimulate knowledge workers' incentives, enthusiasm, and creativities to accomplish tasks of knowledge innovation by a variety of effective methods. In contrast to labors, knowledge workers ask for much more various and high-level requirements including respect, actualization, and self-transcendence beyond the needs of high-quality physical life and spiritual life. Consequently, it is essential to establish numbers of targeted motivation measures to encourage knowledge workers in knowledge-intensive organizations. Some regular practices cover share incentive mechanism, promotion, continuing education, etc., which provide high qualities in living and working for those creative knowledge workers with potential. The positive motivation is preferable to negative motivation in intellectual motivation since knowledge workers would be at risk in process of knowledge innovation and character development. The knowledge-intensive organizations should ignore a few failures and pursue the realization of long-term objectives instead of short-term ones.

\section{Intellectual Controlling and Feedback}

Intellectual controlling is to value, check, and supervise the results and performance of IIM activities in terms of the plan and criterion and then adjust actions or plan according to the deviation. The main contents of intellectual controlling should include personnel 
control, information control, and performance control because of the reasons that knowledge workers are core resources of knowledge-based organizations, information is vital to control overall trends, and performance is the final target of enterprise management. The target of control in traditional enterprises is to reduce deviation or avoid failure, while in process of IlM; it is feasible and fault-tolerant to stimulate the knowledge innovation. In this situation, the probability of fault would be higher. In order to avoid unnecessary losses, the intellectual control must be "just in time". This requirement can be met by IIM based on powerful technologies and techniques. The controlling results would backward feed to the plan departments and leaders rapidly. The outstanding workers or teams should be praised and encouraged to share their experience and knowledge. It would be very conducive to maximizing organizational performance. A complete mechanism of intellectual controlling, evaluating, and backward feeding in knowledge-based organizations is necessary to manage knowledge and characters.

\section{IIM Processes}

According to value chain theory, the business process can be divided into five components including R\&D, logistics, production, marketing, and service (Porter, 1985). In order to give expression to the intellectual character, firms are involved in the management of these businesses and integration of IlM features and advantages. Corresponding to the business process, the process of IIM includes five subprocesses.

\section{R\&D Subprocess of IIM}

The R\&D subprocess is a broad connotation which covers the whole life cycle of new product development from idea creation, product testing to process development. From management perspective, the keys are intellectually managing $R \& D$ strategy, $R \& D$ organizations, and R\&D personnel. From strategic perspective, the R\&D subprocess should pay attention to developing knowledge and characters of products, attracting customers by cultivating brands which are different from rivals, and improving organizational image. The R\&D subprocess of IlM should pay more attention to KM: enhancing R\&D efficiency by knowledge sharing and innovating; increasing knowledge and technologies in products by knowledge creating and utilizing; and being characterized organizations as high-tech or knowledge-based enterprises. On the one hand, innovation is organized by $\mathrm{KM}$ tools to explore and integrate knowledge resources and innovative potential; on the other hand, the individual characters of $\mathrm{R} \& \mathrm{D}$ persons as well as organizational character are integrated into the R\&D subprocess and new products in turn. The characteristic products are developed in the R\&D subprocess of IIM, and thereby, the brand and image are depended on this subprocess too.

\section{Logistics Subprocess of IIM}

Intellectually managing the logistics subprocess is to involve the whole industry chain, which could contribute to the organizations achieving IlM targets and performance, in IIM. Logistics subprocess is a vital process regarding to two segments: the first one is 
the strategic cooperation relations among suppliers, core corporation, and customers; the second one is the control of cost and quality. Suppliers provide resources such as raw materials as well as advanced technologies, information, and knowledge for enterprises. These resources support the characteristic productions and in turn improve organizations' innovation and characters. Meanwhile, supply chain is a main source to control cost and quality. It is necessary to produce first-rate and personalized products through strategic cooperation with suppliers. Most differentiated knowledge-based enterprises, for example, Dell, choose to be different from rivals in terms of supply chain. The distributors, retailers, and customers are important cooperators to intellectually market, advertise and establish brands, and effective channels to collect up-todate customer information and market dynamics, which play obviously significant role in IIM.

\section{Production Subprocess of IIM}

IIM can be applied to production subprocess similarly though it is not as important as other subprocesses in knowledge-based organizations. For example, KM applied in manufacture is in favor of enhancing productivity, improving quality, and reducing costs, and CM applied in characteristic process design raises differentiation advantage in terms of function and quality of products and employee morale. From another point of view, IIM in production subprocess is important to link up IlMs in different business subprocesses since production is a middle subprocess between logistics and marketing. IIM in production subprocess is conducive to IlM strategic targets in different subprocesses coming to an agreement, to avoid "the least of perfection". In this subprocess, the IIM pays attention to items such as job rotation, knowledge contest, flexible job system, knowledge staff career planning, and management of knowledge resources and products. This kind of management, highlighting knowledge features and humanistic management characters of enterprises, is competitive in today's business environment.

\section{Marketing Subprocess of IIM}

Intellectual marketing is an upgrade of knowledge marketing which was proposed at the beginning of KM research. Knowledge marketing which integrates KM into marketing process engages in providing knowledge-based products or services, improving perceived value of customers, and promoting customer satisfaction, and in turn, enhancing corporate core competence. Knowledge marketing is beneficial to customers understanding the high-level knowledge and technologies embedded in products. It is a special kind of differentiated advantage from knowledge perspective. In addition, the differentiated advantage can be promoted based on other marketing concepts such as characteristic marketing, green marketing, brand marketing, conceptual marketing, and service marketing. The target of those marketing concepts is to promote sales from characteristic marketing channels. However, the customer value embedded in marketing subprocess is needed to attract customers and develop markets in any kind of marketing pattern. Intellectual marketing, integrating characteristic marketing into knowledge marketing, embeds knowledge as well as characters in marketing subprocess to gain competitive advantage. Customers would feel the 
intellectual character of high-tech and characteristic products as well as the enterprises that provide these products.

\section{Service Subprocess of IIM}

It is necessary to provide knowledge-intensive and characteristic services to increase the value of products in service subprocess of knowledge-based organizations. It has been over 30 years since service competition was proposed under the condition of intense competition. Knowledge organizations can promote sales of their high-tech products by providing services through which the knowledge and value of products are shared with clients. Organizational characters embedded in service subprocess make enterprises different from rivals in terms of characteristic service mode and stylized service process. Based on behaviors like that, organizational image and character are improved gradually. The IIM in service subprocess engages in sharing intellectual character with customers through intellectual services which are full of added value. Some knowledge-based enterprises such as Sears and Cosco Group have shaped their novel images through service innovation. The main contents of intellectual service include strategizing service, service innovation, service providing, and continual service improvement. Intellectual service which follows the organizational orientation would contribute to achieving strategic objectives. Knowledge-intensive organizations can achieve success in knowledge economy as well as service economy through intellectual service.

\section{IIM Tools}

All tools for KM and CM can be applied to IlM. Some tools regarding external management and internal management, perceptual management, and rational management are involved in IIM too. More novel technologies or techniques need to be developed to achieve the targets of IIM. The tools can be classified as two packages.

\section{Tool Package Regarding to KM, Internal Management, and Rational Decision-Making}

The tools for KM activities such as knowledge acquisition, knowledge sharing, knowledge integration, knowledge innovation, and knowledge utilization support the realization of IlM similarly. Knowledge acquisition technologies include extranet, expert database, Electronic Data Interchange (EDI), data-mining technologies, knowledge base, etc. Knowledge sharing tools cover intranet, cooperative R\&D platform, MIS, and knowledge trading system and so on. Knowledge cataloging and clustering technologies support the knowledge integration activity. Collaborative R\&D platform and intellectual property management techniques are applied to deal with the problems of knowledge innovation process. Some techniques involving in process development, new product development, manufacturing management, and marketing as well as technologies such as web portals can be utilized in subprocess of producing and marketing. On the basis of KM tools, the organizational knowledge resources are transformed into corporate core competence, which is also the target of internal management. Based on information and knowledge provided by expert base, 
knowledge base, and model base, the intelligent decision techniques are applied to the development of Decision Support System (DSS), which supports rational decisionmaking of senior managers.

\section{Tool Package Regarding to CM, External Management, and Perceptual Decision-Making}

All tools regarding CM, external management, and perceptual decision-making can be applied to IIM. Some techniques, for example, emotion management, humanistic organization, talent management, and personalized design, support the proper character of organizations. Other activities such as characteristic management, brand building, and image management in IlM are suitable for showing characters and shaping corporate image. The perceptual decision-making techniques, which cover Brainstorming, Expert Opinion, and Delphi, etc., are relatively mature.

\section{IIM Features}

IlM is a novel management idea which is not only relevant to but also different from the prior management theories. This kind of IlM has its own features as follows.

\section{Open and Networked Organization}

The proper organizational structure should be open and networked to meet requirements of KM and CM. The openness improves understanding and learning cuttingedge and emerging technologies from external environment. For one thing, this interaction between organization and environment is requirement of KM activities such as knowledge learning and collaborative innovation. For another, the interaction is also an important way to show organizational character and intellectual characteristic. The network nodes, knowledge-based talents in enterprises, can share and transfer knowledge rapidly only in networked organizations. Networked organization structure is beneficial to promoting knowledge integration and innovation ability, and meanwhile improving the efficiency and execution of top administrative decisions.

\section{Harmonious and Flexible Mechanism}

According to the He-Xie Management Theory (HXMT), a novel management idea proposed by a Chinese scholar, the harmonious mechanism is essential to surviving in competitive context with characters of complexity, uncertainty and ambiguity (Xi et al., 2012). On the one hand, taking the uncertainty and ambiguity around organizations into account, the He Principle, which focuses on creating organizational culture, values, and beliefs, refers to an evolvement mechanism based on organizational members' initiative and self-determination (Xi et al., 2012). On the other hand, the Xie Principle which engages in promoting organizational development and creating organizational value refers to a control mechanism based on rational design and optimization (Cao et al., 2011). The He Principle is beneficial to improving organizational characters while the Xie Principle is conducive to rational management based on data, information and knowledge. 
Furthermore, a flexible and humanistic motivation mechanism enhances the role of knowledge workers and in turn promotes organizational self-transcendence on the basis of the shared vision. The flexibility is a necessary character of a knowledge-intensive organization. The comfortable and valued feeling is an essential influencing factor to promote knowledge worker's performance within the context of IlM. In addition, the flexible mechanism enhances corporate adaptive capability to environment and stimulates the character development of employees and firms.

\section{Innovative and Shared Culture}

The innovative and shared culture, a key component of IlM, is significant to knowledge sharing and innovation - two core activities of KM. A proper innovative corporation is favor of innovation in terms of organizational environment, corporate value, rules and regulations, and social networks. On the one side, innovative culture covers five elements such as clear and challenging strategy, support from senior managers, participant modeling, synergetic organization, and employment relationship. On the other side, shared culture involves in core idea of knowledge sharing, motivation mechanism, coopetition notion, combination of individual knowledge and organizational knowledge, knowledge communication and exchange among multi-level talents. The integration of innovative culture and shared culture is a precondition of KM and IIM.

\section{Knowledge-Based and Knowledge-Intensive Talents}

The high-tech enterprises which invest in IIM have knowledge-based and knowledgeintensive employees to achieve innovation objectives. Sherman et al. (2005) indicated that knowledge-based enterprises were characterized by high proportion of talents and $\mathrm{R} \& \mathrm{D}$ expenditures. The management methods should be changed in the context of intensive knowledge workers. Knowledge networks among knowledge workers need to be built to promote knowledge flow, integration, collaboration, and innovation, by formal or informal organizational patterns. According to demand theory, knowledgebased talents pursue high-level satisfactions. Hence, managers should create better conditions such as relaxed culture, development platform, cooperation environment, humanistic care and spiritual motivation for the talents. Furthermore, the characters of talents tend to be diverse and implicit. Relaxed environment and beneficial atmosphere are required to control the development of employees' characters. It would be much more creative to innovate when individual demands on spiritual life and career development are satisfied.

\section{Intellectual and Social Capital}

Intellectual capital and social capital are significant to knowledge-based organizations, in addition to a mass of financial capital. Intellectual capital, which covers human capital, relational capital, structural capital and innovative capital, supports knowledge innovation and intelligent image of organizations (Guthrie et al., 2012). Those capitals are management objects as well as inputs and outputs of IlM. The intellectual resources carried by talents, organizations, and systems are integrated and innovated to create value. Furthermore, the capital of knowledge-based organization is characterized by 
high rate of social capital. Items such as trust and the norm of reciprocity are foundation of KM (Ahmadi et al., 2011). The organizational character is also required united social relationship networks. Intellectual capital can be created by KM while social capital depends on the state of CM. In this context, business mind and intellectual characteristic would appear and develop in knowledge-based organizations gradually.

\section{Conclusions}

Knowledge is one of the most important resources of enterprises in the era of knowledge economy. However, in the fierce competition context, customers require personalized services as well as knowledge-based products. The knowledge and character play similarly significant roles in organizations. Knowledge-intensive organizations need a kind of management theory which can provide core competence as well as character competence. Taking this into consideration, a novel IlM theory was proposed in this study on the basis of comprehensive analyses of CM and KM.

Through case study of three Chinese famous enterprises, the important of integration of $\mathrm{KM}$ and $\mathrm{CM}$ was clearly described. The main contents and implementation process of a proper management were discussed in detail. Based on the comparative analysis in terms of management level, function, process, tool, and feature, the results and findings were summarized and then the theoretical model of IlM was built.

IlM was defined as five levels including foundation level, organization level, operation level, platform level, and realization level. In other words, IlM is a kind of theory which absorbs the ideas of $\mathrm{KM}$ and $\mathrm{CM}$ to deal with internal and external events. The modes of IIM are perceptual management and rational management, and this theory is implemented on the basis of modern information technologies. The IIM aims to realize the targets of internal growth and characteristic development. This new management technique is not implemented independently. The best application pattern is to embed the IlM ideas in prior management systems including functions (e.g., strategizing, leading, motivating, controlling, etc.) and processes (e.g., R\&D, logistics, production, marketing, etc.). No matter which kind of specific implementations, organizations which engage in IlM would show different features. It is certain that a proper IlM would bring organizations core competence and sustainable competitive advantage, which is a really important to long-term development of organizations.

The research limitations can be found in the possibility of more in-depth research and more communications and discussions. Obviously, decisions regarding the proposition of a new conceptual management theory were limited by the bibliographic research. More in-depth research is needed to enrich this totally novel theory. The IIM theory proposed in this paper requires more case studies especially the cases in different cultural contexts. Furthermore, empirical study is required to test the validity of IIM and its impact on management performance. Management technologies, techniques, and tools are expected to be developed to promote its implementation.

The main implications of this study are for professionals concerning management theoretical innovation and innovative management practices. The management theory proposed in this paper has integrated so many essential management thoughts, and therefore, it might provide a great inspiration for some professionals. The ideas of this theory may be applied to improving the prior management theories or optimizing 
systems of some knowledge-based organizations. Some practitioners may begin to rethink the strategy, positioning, or management style in the past. What is the most desired is that much more theoretical research achievements, no matter positive or negative, would be reported by the inspiration of this paper.

Acknowledgements This study was funded by NSFC Projects (grant number 71201072; 71563027) and Social Science Project of Jiangxi Province (grant number 14GL09). The China Scholarship Council was also appreciated for its support on research communication.

Conflict of Interest The authors declare that they have no competing interests.

Open Access This article is distributed under the terms of the Creative Commons Attribution 4.0 International License (http://creativecommons.org/licenses/by/4.0/), which permits unrestricted use, distribution, and reproduction in any medium, provided you give appropriate credit to the original author(s) and the source, provide a link to the Creative Commons license, and indicate if changes were made.

\section{References}

Ahmadi, A. A., Eskandari, E., \& Ahmadi, F. (2011). Social capital for knowledge management. Interdisciplinary Journal of Contemporary Research In Business, 3(7), 957-972.

Barboza, D. (2005), "Hunan TV cancels the bland to bring the offbeat to China", International Herald Tribune, 28 November 2005, 13

Becerra-Fernandez, I., \& Sabherwal, R. (2010). Knowledge management: systems and processes. Armonk: M.E. Sharpe.

Bosworth, D. L., \& Webster, E. (2006). The management of intellectual property. North Hampton: Edward Elgar.

Bruque, S., HernÁNdez, M. J., Vargas, A., \& Moyano, J. (2003). Ownership structure, technological endowment and competitive advantage: do democracy and business fit? Technology Analysis \& Strategic Management, 15(1), 65-79.

Bukh, P. N. D., Christensen, K. S., \& Mouritsen, J. (2005). Knowledge management and intellectual capital: establishing a field of practice. New York: Palgrave Macmillan, Houndmills.

Cao, X., Zhang, X., \& Xi, Y. (2011). Ambidextrous organization in harmony: a multi-case exploration of the value of HeXie management theory. Chinese Management Studies, 5(2), 146-163.

Chatti, M. A. (2012). Knowledge management: a personal knowledge network perspective. Journal of Knowledge Management, 16(5), 829-844.

Chen, J. A. (2014). "Which characters of knowledge-based employees have higher turnover intension in Chinese culture industry?". Open Journal of Social Sciences, 2, 18-27.

Chuang, S. H. (2004). A resource-based perspective on knowledge management capability and competitive advantage. Expert Systems with Applications, 27(3), 459-465.

Collinson, S., \& Rugman, A. M. (2007). "The regional character of Asian multinational enterprises". Asia Pacific Journal of Management, 24, 429-446.

Combe, C. (2014). Introduction to management. Oxford: Oxford University Press.

Cooter, R., \& Eisenberg, M. A. (2001). Fairness, character, and efficiency in firms. University of Pennsylvania Law Review, 149(6), 1717-1733.

Dave, B., \& Koskela, L. (2009). Collaborative knowledge management-a construction case study. Automation in Construction, 18(7), 894-902.

De Cremer, D., \& Zhang, J. (2014). Huawei to the future. Business Strategy Review, 25(1), $26-29$.

Ding, L. (2011). Transition of China's growth pattern. Frontiers of Economics in China, 6(4), 535-555.

Fisher, W. W., III, \& Oberholzer-Gee, F. (2013). Strategic management of intellectual property: an integrated approach. California management review, 55(4), 157-183.

FORTUNEChina (2014), "The 2014 Global 500 companies lists", available at: www.fortunechina.com.

Foster, W. A., \& Reinsch, R. C. (2010). Huawei's leadership role in IMS standards development and in its own proprietary Softswitch. Chinese Management Studies, 4(4), 297-304.

Goffee, R., \& Jones, G. (1998). The character of a corporation: how your company's culture can make or break your business. London: Harper Collins. 
Gold, A. H., Malhotra, A., \& Segars, A. H. (2001). Knowledge management: an organizational capabilities perspective. Journal of Management Information Systems, 18(1), 185-214.

Guthrie, J., Ricceri, F., \& Dumay, J. (2012). Reflections and projections: a decade of intellectual capital accounting research. British Accounting Review, 44(2), 68-82.

Hawryszkiewycz, I. (2010). Knowledge management: organizing knowledge based enterprises. New York, Basingstoke: Palgrave Macmillan.

He, X. (2012). Three campaigns: the Waterloo of Giant Group. Modern Reading, 1, 68-69.

Henard, D. H., \& McFadyen, M. A. (2006). R\&D knowledge is power. Research Technology Management, 49(3), 41-47.

Huawei. (2011). Internal control manual of Huawei company. Shenzhen, Guangdong: Huawei Technologies Co. Ltd.

Huawei. (2014). 2013 Huawei annual report. Shenzhen, Guangdong: Huawei Technologies Co. Ltd.

Isaac, R. G., Herremans, I. M., \& Kline, T. J. (2010). Intellectual capital management enablers: a structural equation analysis. Journal of Business Ethics, 93(3), 373-391.

Jacques, R. (1996). Manufacturing the employee: management knowledge from the 19th to 21st centuries. Thousand Oaks: Sage Publications.

Jashapara, A. (2011). Knowledge management: an integrated approach. New York: Pearson/Financial Times/ Prentice Hall, Harlow, Essex.

Jennewein, K. (2004). Intellectual property management: the role of technology-brands in the appropriation of technological innovation. New York: Physica-Verl, Heidelberg.

Kale, S., \& Karaman, E. A. (2011). Evaluating the knowledge management practices of construction firms by using importance-comparative performance analysis maps. Journal of Construction Engineering and Management, 137(12), 1142-1152.

Kant, I., Louden, R.B., Zöller, G. (2007), Anthropology, history, and education. Cambridge University Press, GB.

Klann, G. (2007). Building character: strengthening the heart of good leadership. San Francisco: Jossey-Bass.

Lee, H., \& Choi, B. (2003). Knowledge management enablers, processes and organizational knowledge. Journal of Management Information Systems, 20(1), 179-228.

Li, G. (2010). Technological innovation makes Huawei successful. China Hi-Tech Enterprises, 7, 96-97.

Liu, H. (2008). Internal controls of Giant Group. Financial Supervision, 10, 25-28.

Low, B. (2007). Huawei Technologies Corporation: from local dominance to global challenge? Journal of Business \& Industrial Marketing, 22(2), 138-144.

Lv, J., \& Yu, X. (2008). The strategy and enlightenment of HSTV's brand development. Modern Economy, $7(13), 120-122$.

Miao, Q. (2007). Technological innovation management of Huawei Technologies Co. Wuhan, Hubei: Department of Philosophy of Science and Technology, School of Politics and Administration. Wuhan Insititute of Technology.

Moore, G. (2005). Corporate character: modern virtue ethics and the virtuous corporation. Business Ethics Quarterly, 15(4), 659-685.

O'Dell, C., \& Grayson, J. (1997). If we only knew what we know: identification and transfer of internal best practices. Houston: American Productivity and Quality Center.

Ofek, E., \& Sarvary, M. (2001). Leveraging the customer base: creating competitive advantage through knowledge management. Management Science, 47(11), 1441-1456.

Ostapov, Y. (2012). Intellectual management of enterprise. available at: http://qut.summon. serialssolutions.com.

Ouyang, J. (2008). The troika for building and developing HSTV channel. Southeast Communication, 8, 114 115 .

Porter, M. E. (1985). Competitive advantage: creating and sustaining superior performance. New York: Free Press.

Resnick, J. T. (2003). Character is foundation of firm's reputation. U.S. Banker, 113(3), 24-26.

Rosenthal, E. (2000). Hunan style television: spicy and crowd pleasing. The New York Times. 11 October 2000, A4.

Schermerhorn, J.R., Jr., Davidson, P., Poole, D., Woods, P., Simon, A., McBarron, E. (2014), Management. John Wiley and Sons Australia, Ltd, Milton, Qld.

Sharma, S. (2002). Character competence of the corporation. Journal of Human Values, 8(2), 107-118.

Sherman, D. J., Berkowitz, D., \& Souder, E. W. (2005). New product development performance and the interaction of cross-functional integration and knowledge management. The Journal of Product Innovation Management, 22, 399-411.

Simon, H. A. (1977). The new science of management decision. Englewood Cliffs: Prentice-Hall. 
Smith, E. A. (2001). The role of tacit and explicit knowledge in the workplace. Journal of Knowledge Management, 5, 311-321.

Soriano, D. R. (2003). Modeling the enterprising character of European firms. European Business Review, $15(1), 29-37$.

Steinbock, D. (2013). Huawei’s american dream (pp. 44-55). Beijing: China Economist. Institute of Industrial Economics Chinese Academy of Social Sciences.

Stout, L. A. (2012). The shareholder value myth: how putting shareholders first harms investors, corporations, and the public. San Francisco, Cailf: Berrett-Koehler.

Tserng, H. P., \& Chang, C. H. (2008). Developing a project knowledge management framework for tunnel construction: lessons learned in Taiwan. Canadian Journal of Civil Engineering, 35(4), 333-348.

Vance, A., \& Einhorn, B. (2011). At Huawei, Matt Bross tries to ease U.S. Security fears. available at: www. businessweek.com.

Wang, Q., \& Tian, X. (2009). Inspirations of Giant Group's rise and decline. Western Coal Chemical Industry, $1,68-69$.

Wenping, W. (2004). Organic mechanism and capacity grey set optimization for knowledge-based enterprise. Kybernetes, 33(2), 372-381.

Whyte, M., \& Zyngier, S. (2014). Applied intellectual capital management. Journal of Intellectual Capital, 15(2), 227-248

Wiig, K. M. (1993). Knowledge management foundations: thinking abour thinking - how people and organizations create, represent and use knowledge. Arlington: Schema Press.

Wright, T. A., \& Goodstein, J. (2007). Character is not "dead" in management research: a review of individual character and organizational-level virtue. Journal of management, 33(6), 928-958.

Xi, Y., Zhang, X., \& Ge, J. (2012). Replying to management challenges: integrating oriental and occidental wisdom by HeXie management theory. Chinese Management Studies, 6(3), 395-412.

Yi, L., \& Xiang, J. (2012). HSTV: a ten-year brand innovation. Admen, 6, 84-96.

Yu, X., Chen, Y., \& Wang, L. (2008). The financial management problems of SMEs: the case of Giant Group. Journal of Jilin Province Economic Management Cadre College, 4, 82-84.

Zhou, Q. (2002). Shi Yuzhu and his Giant Group. Business and Law, 1, 46-47. 